\title{
Mangrove Ecosystem Services: Indus Delta (PQA), Sindh
}

\author{
Shahid Amjad, Muhammad Ajaz Rasheed, Mirza Aqeel Baig \\ Institute of Business Management (IoBM), Karachi, Pakistan \\ Email: Shahid.amjad@iobm.edu.pk
}

Received 24 February 2016; accepted 27 July 2016; published 30 July 2016

\begin{abstract}
Mangroves of the Indus Delta are the world's fifth largest assemblage, and the largest in the arid zone. Mangroves of Indus delta (PQA) provide immense benefits, products and unrecognized regulatory services. Products of Direct Economic Value: Fish, Minerals and food. There are Products of Natural System (intangible) supplies of rich nutrients to support productivity. Coastal communities benefit in a multitude of ways from Mangrove ecosystems. Collectively, these benefits are known as ecosystem services. The ecological role of mangrove ecosystems in the Indus Deltaic area of Port Qasim Authority (PQA) is, economically and socially significant. The Mangroves are well known for their high biological productivity and their consequent importance provided to the coastal community in terms of services and products of direct and indirect value to the adjacent coastal waters. Mangrove Ecosystem services are regularly involved in the provisioning of food and services and the decomposition of organic wastes. They export organic matter, mainly in detritus form of leaf litter to the marine environment, thus providing a highly nutritious food source for themselves and for the Benthic and terrestrial animals found in the mangrove areas, as well as for those in neighboring estuarine and marine ecosystems. Apart from nutrient export, mangroves also contribute to offshore fisheries by acting as nurseries and shelters for many species of commercially important finfish and crustaceans. Degradation of Indus Deltaic mangrove in PQA would destabilize the economic potential and the livelihood of communities' which include services and benefits offered by the mangrove ecosystem. Rehabilitation and conservation of mangroves ecosystem in PQA is essential for sustained biological productivity in the region.
\end{abstract}

\section{Keywords}

Mangrove Ecosystem Services, Biological Productivity, Coastal Communities

\section{Introduction}

The present Indus Delta covers an area of about 263,000 hectares and is characterized by 16 major creeks and innumerable minor creeks, dominated by mud flats, and fringing mangroves. The coastal morphology is characterized by a network of tidal creeks and a number of small islands with sparse mangrove vegetation, mud banks, swamps, and lagoons formed because of changes in river courses. The Port Qasim Authority has administrative control over 64,000 ha of mangrove forests, mud flats and creeks, 4900 ha of land are above the high water mark 
(+3.4 m.) [1]. The major land use of the area adjoining the site includes industrial zones and port areas. The numerous estuaries and creeks connecting to the sea which characterize the tidal delta and marshy mud flats, do not receive the same quantities of nutrients that they used to get in the past to support the growth of mangroves and aquatic life. PQA is part of the Indus Delta that currently supports one of the largest single mangrove ecosystems in the tropical coastal environments. In the Indus Delta mangrove ecosystem, eight species of mangroves have been reported The Avicenna marina is the dominant species of the mangroves in the Indus Delta that grows on the northern and southern banks of the Phitti Creek. The Mangroves are highly nutritious food source for marine fauna. Mangroves provide a habitat and breeding ground for a variety of marine life, particularly fish, shrimps and crabs.

\section{Study Area}

The Karachi coastline between Korangi creek inlet and Kadiro Creek encompasses three islands; Bundal Island, Buddo Island and Khiprianwala Island and two large and deep openings towards the sea viz. Phitti Creek Mouth (Approach channel of Port Qasim) and the Kadiro Creek Mouth. The geographical location is given in Figure 1. The eastern coast has tidal creeks with mangrove and mudflats which are linked with a network of creeks of Indus Delta.The Port Qasim Authority consists of three major creeks systems, the GharoPhitti Creek System: Gharo Creek, Kadiro Creek and Phitti Creek. All three are connected in a series starting from Gharo Creek at the north-eastern end to the Phitti Creek at the south-western end and located at $22.3 \mathrm{~km}$ from Karachi. This creek system is about $28 \mathrm{~km}$ long and its width ranges from 250 to $2500 \mathrm{~m}$. The Korangi Creek and Kadiro Creeks are connected with it at the north-eastern end while it acts as main waterway connected with the open sea at the south-western end. The main channel of Port Bin Qasim lies in this creek system, which has been dredged to maintain a navigable depth of -11.3 meters.

The sampling location and coordinates in the PQA area for the observing the mangrove tree heights, densities and biodiversity sampling locations are given in Table $\mathbf{1}$.

\section{Mangrove Ecosystem Services}

Avicenna marina is the most dominant species. Other mangrove species in the deltaic region such as the Ceriopstagal occur in localized patches and there are a few plants of Rhizophora mucronata. All other species are rare and have disappeared from most part of the Delta due to adverse environmental conditions. The mangrove trees growing 200 - $300 \mathrm{~m}$ away from the creek (seawater) in the land ward direction show an overall decline in the height of the mangrove plantations. Destabilization of mangroves in the Indus Delta has been attributed to the progressive reduction in fresh water discharge over a period of many years. Historical records indicate that the distribution of mangroves in the Indus Delta has significantly changed during the past several hundred years
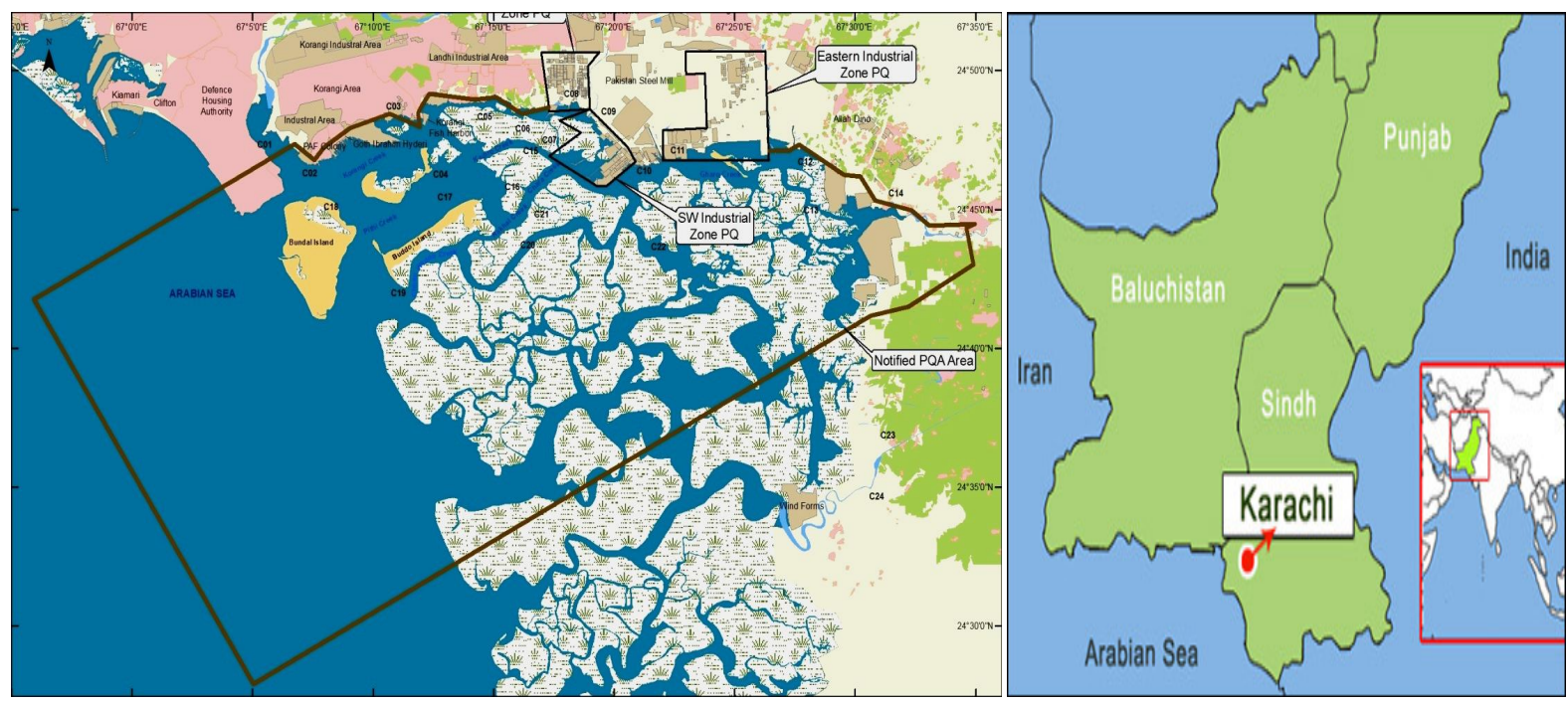

Figure 1. Geographical location and Study Area, Sought of Karachi Port Qasim Area, part of the Indus Delta, Sindh. 
Table 1. Sampling stations and coordinates.

\begin{tabular}{ccc}
\hline Station No & Latitude $\mathbf{~}$ & Longitude E \\
\hline EC 1 & 244837.8 & 671457.2 \\
EC 2 & 244814.7 & 671645.5 \\
EC 3 & 244612.6 & 672519.4 \\
EC 4 & 244353.1 & 671450.3 \\
EC 5 & 244345.9 & 672113.2 \\
EC 7 & 243751.8 & 67179.0 \\
EC 11 & 244623.9 & 671250.7 \\
\hline
\end{tabular}

with the shifting pattern of the river [2]. Until recently the Indus River had a largely river-dominated estuary but increased utilization of the river for agriculture etc. has resulted in discharge to the Arabian Sea only during the summer southwest monsoon. During remaining nine to ten months the Indus River has no estuary due to elimination of the river discharge [3]. As a result, the Indus delta mangrove ecosystem has been adversely affected. The mangroves are degrading rapidly caused by a number of factors such as cutting, browsing and by reduced silt laden river water. The mangrove forests which covered 263,000 ha in 1977 recessed to about 160,000 ha in 1990 [4], threatening the survival of the natural resources and thereby the livelihood of a large number of fisherman. The current mangrove cover in the Indus delta and the PQA shows an increase in mangrove forest by $3.17 \%$ from $94.18 \%$ (2005) to $97.35 \%$ in 2015 (2015 SPOTXS) (Table 2).

\section{Nutrient Concentration}

The standing stock of plant biomass represents the "natural capital” of the PQA ecosystem that is combined with nutrients, water, and abiotic components to maintain the existing biomass, and create new biomass essential for the well being of the Indus delta.

The nutrients including Phosphate, Nitrate, Nitrite and Ammonia play a vital role in the food chain of marine ecosystem in primary production of coastal and oceanic waters.

They support the growth of phytoplankton which serve as the food for zooplankton as well as larval stages and juveniles of fish and crustaceans, they also serve as food for filter feeders and benthic marine invertebrate (MBI). The Gharo/Phitti creek in PQA receive large quantities of nutrients as part of the sewage effluent and garbage that is disposed off in these creeks. Nutrients in the PQA do not appear to be limiting to primary productivity in the channels. If there is any limitation, it is due to water turbidity that restricted the photic zone. Higher concentrations of nutrients result in overproduction and subsequently leading towards exhaustion of dissolved oxygen in the seawater.

The Primary Productivity values from literature for the months of February, March, and June show relatively higher productivity rates for PQA area. The overall Productivity in the mangrove areas is reported to be high (365 - $780 \mathrm{gC} / \mathrm{m}^{2} /$ year, [6], compared to coastal waters (50 - $200 \mathrm{gC} / \mathrm{m}^{2} /$ year), which accounts for greater potential for fisheries yield in the PQA (64,000 ha) mangrove area (Table 3).

\section{Mangroves Tree Heights and Densities}

Despite their strategic importance, mangroves are among the most threatened and rapidly disappearing natural environments in the world. Mangroves are a valuable resource for many of the coastal villages. They are primarily used as a source of fuel and fodder and provide the feeding grounds for shrimp, besides protecting the land from erosion. The people have been overexploiting this resource over the years. IUCN has, in association with Sindh Forestry Department, initiated a program of mangrove conservation, replanting and sustainable management along the coastline of Rehri village, and CSR of PQA industrial area, for every mangrove tree felled, five mangrove sampling have to be planted (SEPA 2014) under the supervision of a third party (IUCN/WWF). Mean tree heights of Avicenna marina in PQA at seven randomly selected locations ranged from 2 - 6 m (Figure 2(a)). The mangroves density ranges $4-9 / 10 \mathrm{~m}^{2}$ (Figure 2(b)). Data of mangrove tree height from seven locations 
Table 2. The area summary of Mangrove forests along the coast of Pakistan based on SPOT XS data 2015 [5].

\begin{tabular}{cccc}
\hline Region & Area in Hectares & Area in Acres & \% \\
\hline Karachi Harbour Area & 985.5 & 2434.185 & 0.51585 \\
Indus Deltaic Region \& PQA & 186000 & 459420 & 97.35984 \\
MianiHor & 3431.36 & 8475.459 & 1.796111 \\
KalmatHor & 194 & 497.18 & 0.101547 \\
Jiwani & 433 & 1069.51 & 0.2265 \\
Total & 191043.86 & 471896.334 & 100 \\
\hline
\end{tabular}

Table 3. Primary productivity and Potential fish productivity in the PQA area.

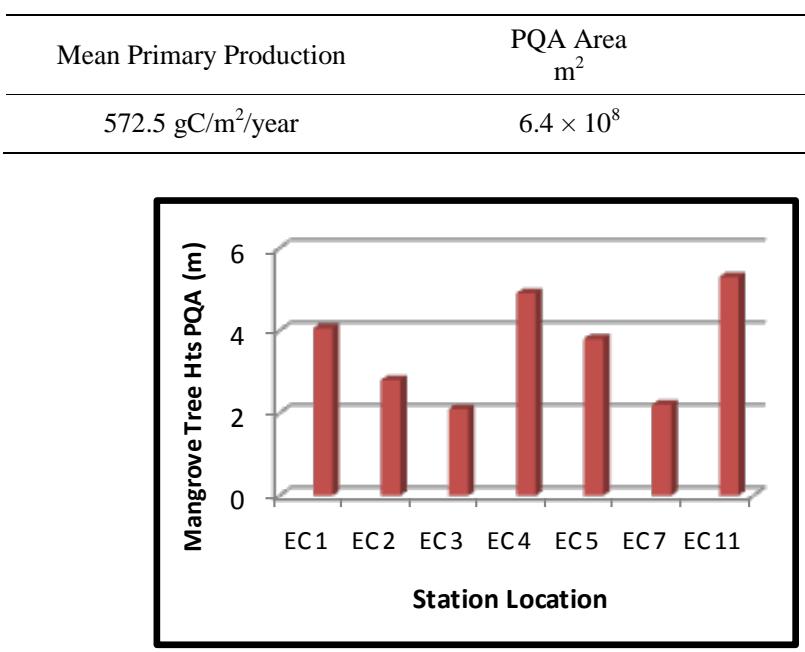

(a)

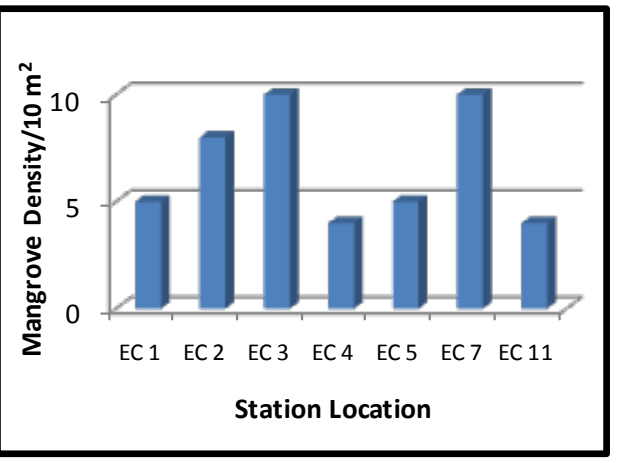

(b)

Figure 2. (a) \& (b) Avicenna marina tree heights and no of trees per $10 \mathrm{~m}^{2}$ PQA.

was subject to ANOVA (Table 4). The results indicate significant difference $(\mathrm{p}<0.05)$, between mangrove (Avicenna marina) tree heights.

The mangroves plants have a high biological productivity and are important to the nutrient budget of coastal waters. They export organic matter, mainly in detritus form (i.e. leaf litter) to the marine environment, thus providing a highly nutritious food source for marine fauna. Mangroves provide a habitat and breeding ground for a variety of marine life, particularly fish, shrimps and crabs. Since they act as nurseries and shelters for many species of commercially important finfish and crustaceans they are important for maintaining offshore fishery, as well as habitat for wildlife, such a loss would reduce available habitat for birds and juvenile fish, and the biodiversity of the local plants and benthic marine invertebrates.

\section{Shannon Weiner Diversity Index}

Shannon Weiner diversity index is a tool for measuring the health of the ecosystem. Benthic Marine Invertebrate sample at stations EC 4 (1.146) and EC 7 (1.0) show a relatively higher biodiversity of MBI in PQA (Diversity ranges from 0.1 - 3.0). The MBI species show a relatively even distribution at sampling stations EC 1 (0.841), EC 3 (0.898). The normal range for evenness (J') is from 0.1 to 1.0. PQA is a designated industrial area, creeks system are a disturbed due to industrial activity, and therefore both species diversity and species richness are relatively low (Table 5).

\section{Employment and Living Conditions}

PQA and its environs do not offer opportunities for employment and the population is primarily employed as 
Table 4. Results of ANOVA on Avicenna marina (Mangrove heights) in PQA.

\begin{tabular}{ccccc}
\hline \multicolumn{5}{c}{ ANOVA } \\
\hline \multicolumn{5}{c}{ Avicenna marina (Mangrove heights ) in PQA } \\
\hline Sum of Squares & Mean Square & F & Sig. \\
\hline Between Groups & 48.407 & 8.068 & 8.566 & 0.000 \\
Within Groups & 26.372 & 0.942 & & \\
Total & 74.779 & & & \\
\hline
\end{tabular}

Table 5. Shannon Weiner Diversity Index in for marine benthic invertebrates PQA.

\begin{tabular}{cccccccc}
\hline Index & EC 1 & EC 2 & EC 3 & EC 4 & EC 5 & EC 7 & EC 11 \\
\hline Shannon H' Log Base 10. & 0.802 & 0.161 & 0.628 & 0.274 & 0.577 & 0.418 & 0.201 \\
Shannon Hmax Log Base 10 & 0.954 & 0.778 & 0.699 & 1.146 & 0.903 & 1 & 0.699 \\
Shannon J' & 0.841 & 0.207 & 0.898 & 0.239 & 0.639 & 0.418 & 0.288 \\
\hline
\end{tabular}

cheap unskilled labor force in the industrial areas of PQA. Agriculture is limited to subsistence farming due to scarcity of water. In Juma Goth and areas close to Cattle Colony there is extensive cultivation of vegetables using the effluent from the cattle yards. Livestock herding is not a healthy and reliable income generating option, and the few livestock holdings in the settlements are primarily for household and domestic use, a source of dairy consumables. Skilled labor is rare and the categories of skilled laborers are mostly drivers, welders, plumbers and electricians. Government service is rarely available.

The Settlements in the Korangi Creek area are fishermen, but the village dwellers are engaged in other low level occupations as well. The employment, and therefore the earnings for a large section of population in the area is variable, dependent on, fisheries, shrimp and crab fishing from inshore waters and collection of mangroves as fodder for domesticanimal is the main source of income. However, a substantial segment of population is employed on deep-sea fishing boats.

\section{Conclusion}

The ecological role of mangrove ecosystems PQA is, economically and socially, highly significant. The Mangroves are well known for their high biological productivity and their consequent importance to the nutrient budget of adjacent coastal waters. They export organic matter, mainly in detritus form to the marine environment, thus providing a highly nutritious food source for themselves and for the Benthic and terrestrial animals found in the mangrove areas - as well as for those in neighboring estuarine and marine ecosystems. Thus, they support local and commercial fisheries yields. Apart from nutrient export, mangroves also contribute to offshore fisheries by acting as nurseries and shelters for many species of commercially important finfish and crustaceans. While a positive correlation between mangrove areas and fish productivity is acknowledged, the scientific information on this relationship is lacking.

\section{Acknowledgements}

The current study is a part of the IUCN small grant project on Valuation of Mangroves in PQA Indus Delta: An Econometric Approach. The authors acknowledge the support and assistance of IUCN Karachi and IoBM EMEC for their continued support.

\section{References}

[1] ESIA EngroVopak EMC Report 2014.

[2] Snedaker, S.C. (1984) Mangrove: A Summary of Knowledge with Emphasis on Pakistan. In: Haq, B.U. and Milliman, J.D., Eds., Marine Geology and Oceanography of Arabian Sea and Coastal Pakistan, Van Nostrand Reinhold Com- 
pany Inc., NY, 255-262.

[3] Schubel, J.R. (1984) Estuarine Circulation and Sedimentation: An Overview. In: Haq, B.U. and Milliman J.D., Eds., Marine Geology and Oceanography of Arabian Sea and Coastal Pakistan, Van Nostrand Reinhold Company Inc., NY, 113-136.

[4] Qureshi, T. (2005) Mangroves of Pakistan: Status and Management. IUCN. Pakistan.

[5] Qureshi, T. (2016) Mangroves of Pakistan: Issues \& Recommendations PCST MoST (Manuscript in Press).

[6] Intergovernmental Oceanographic Commission (IOC) International Workshop on Integrated Coastal Zone Management (ICZM) Workshop Report No. 114, Karachi, Pakistan 10-14 October 1994.

\section{Submit or recommend next manuscript to SCIRP and we will provide best service for you:}

Accepting pre-submission inquiries through Email, Facebook, LinkedIn, Twitter, etc.

A wide selection of journals (inclusive of 9 subjects, more than 200 journals)

Providing 24-hour high-quality service

User-friendly online submission system

Fair and swift peer-review system

Efficient typesetting and proofreading procedure

Display of the result of downloads and visits, as well as the number of cited articles

Maximum dissemination of your research work

Submit your manuscript at: http://papersubmission.scirp.org/ 